\title{
Importance of context in management of behavioral symptoms of dementia
}

\section{Mini Review}

The four main progressive neurodegenerative diseases are Alzheimer's disease, vascular dementia, Dementia with Lewy bodies and Frontotemporal degeneration. Although there are some differences in early stages of these diseases, in the moderate and late stages the symptoms are very similar. In addition, autopsy results indicate that many persons dying with dementia have pathological changes in their brain indicating presence of more than one pathological processes. Therefore, management of behavioral symptoms in moderate and late stages of these diseases may use similar strategies.

Behavioral symptoms of these diseases are often the most difficult symptoms to manage and are often a reason for institutionalization. Development of effective management strategies is hindered by confusing terminology. Research investigating treatments often use "agitation" or "behavioral and psychological symptoms of dementia (BPSD)" as an outcome measure without differentiating the context in which these behaviors occurred. Actually, a recent review of 85 measures, used for assessing behavioral symptoms of dementia, found that "no measures identify risk factors for behaviors or enable an evaluation of the context in which behaviors occur". ${ }^{1}$ At the same time, it is recognized that there is a need for identification of context in which behavior occurred for effective management as is described in the DICE approach. ${ }^{2,3}$

The most important context in which behavior occurs is presence or absence of another person. This context can distinguish two main types of behaviors: agitation and rejection of care. ${ }^{4}$ Agitation can be defined as "behaviors that communicate to others [who observe the patient] that the patient is experiencing and unpleasant state of excitement and which remain after interventions to reduce internal or external stimuli have been carried out". ${ }^{5}$ i.e., medical conditions, pain, medication side-effects, environmental factors, hunger or thirst, and others. Symptoms of agitation include general restlessness, repetitive mannerisms, pacing, trying to get to a different place, handling inappropriately, hiding things, inappropriate dressing and undressing and repetitive sentences. ${ }^{6}$ Agitation occurs when the person with dementia does not interact with others, i.e., is solitary.

Rejection of care occurs in most cases when a caregiver tries to provide care for a person who does not understand the need for it, or misperceives the action as threatening, and resists caregiver's actions. $^{7}$ If the caregiver insists to provide care, the person with dementia may defend himself/herself from unwanted attention, may become combative and develop reactive aggression. This reactive aggression can be defined as "the repertoire of behaviors with which persons with dementia withstand of oppose the efforts of a caregiver". 8 and includes hitting, pushing, scratching, grabbing things or people, kicking and biting, screaming, cursing, temper outbursts, and making strange noises. ${ }^{9}$

The main difference between agitation and aggression is that agitation occurs when the person does not interact with others, while reactive aggression occurs during such interactions. This difference is
Volume I Issue 3 - 2017

\author{
Ladislav Volicer \\ School of Aging Studies, University of South Florida, USA
}

Correspondence: Ladislav Volicer, School of Aging Studies, University of South Florida, USA, Tel 8| 3-909-0539, Email Ivolicer@usf.edu

Received: October 28, 2017 | Published: May 12, 2017

supported by the Minimum Data Set 3.0 evaluations that distinguishes behavioral symptoms not directed towards others, and physical and verbal behavioral symptoms directed towards others. ${ }^{9}$ Rejection of care is not only stressful for nursing aids as is described in an excellent article by Morgan et $\mathrm{a}^{10}$ but also for informal caregivers of persons with dementia living at home. ${ }^{11}$

It is important to distinguish agitation and aggression because non-pharmacological management differs in these two syndromes. Agitation may be decreased or eliminated by providing meaningful activities, ${ }^{12,13}$ by aromatherapy with massage, ${ }^{14}$ and by other activities. ${ }^{15}$ In contrast, reactive aggression requires improved communication or changes in care strategies. ${ }^{16}$ If non-pharmacological measures are not successful in treatment of agitation and reactive aggression, the FDA approved medications for treatment of Alzheimer's disease may be used. ${ }^{17}$ Both cholinesterase inhibitors and memantine may decrease agitation, apathy and reactive aggression. ${ }^{18,19}$ Memantine may also decrease apathy in frontotemporal dementia ${ }^{20,21}$ and addition of memantine to a cholinesterase inhibitor improved apathy treatment in Alzheimer's disease. ${ }^{22}$

If these medications are not effective and there is an evidence of depressed mood, antidepressant treatment may be indicated because depression is a risk factor for both agitation and reactive aggression. ${ }^{23,24}$ Depression is often underdiagnosed and undertreated in persons with dementia. ${ }^{25,26}$ Antidepressant citalopram is effective in treatment of behavioral symptoms of dementia ${ }^{27,28}$ but other antidepressants may be less effective. In the DIADS study, investigating effects of sertraline, behavioral symptoms of dementia were improved only if the depression was alleviated. ${ }^{29}$ It is known that a single medication treatment for depression is effective only in one third of cognitively intact patients ${ }^{30}$ and similar degree of effectiveness could be expected also in persons with dementia. Therefore, antidepressants may have to be combined with an atypical antipsychotic to achieve a full antidepressant effect. ${ }^{31}$

Another indication for use of antipsychotics is a presence of delusions or hallucinations that are bothersome to the person with dementia, and may be dangerous to the person or others. Many antipsychotics are effective in reducing behavioral symptoms of dementia ${ }^{32}$ but their use should be limited because of serious side effects including increased mortality ${ }^{33}$ and sudden cardiac death. ${ }^{34}$ 
However, lower doses may be required when antipsychotics are used to enhance effects of antidepressants and this may decrease the risk of side effects.

Methods for treatment of behavioral symptoms of dementia are evolving and there are several trials of medications investigating their effects in persons with dementia. ${ }^{35}$ These trials should take into consideration context of the behaviors and distinguish agitation and rejection of care/aggression. Taking into consideration context in which behaviors occur, may result in an FDA approved medications that may facilitate treatment of behavioral symptoms and improve quality of life of persons with dementia.

\section{Acknowledgements}

None.

\section{Conflict of interest} article

Author declares there is no conflict of interest in publishing the

\section{References}

1. Gitlin LN, Marx KA, Stanley IH, et al. Assessing neuropsychiatric symptoms in people with dementia: a systematic review of measures. Int Psychogeriatr. 2014;26(11):1805-1848.

2. Kales HC, Gitlin LN, Lyketsos CG. Management of Neuropsychiatric Symptoms of Dementia in Clinical Settings: Recommendations from a Multidisciplinary Expert Panel. J Am Geriatr Soc. 2010;62(4):762-769.

3. Kales HC, Gitlin LN, Lyketsos CG. Assessment and management of behavioral and psychological symptoms of dementia. BMJ. 2015. p. 350-369.

4. Cohen MJ, Jensen B. Journal of the American Medical Directors Association. 2008;(9):552-557.

5. Hurley AC, Volicer L, Camberg L, et al. J. Mental Health Aging. 1999;(5):117-133

6. International Psychogeriatric Assocition (IPA). Behavioral and Psychological Symptoms of Dementia (BPSD). Educational Park, USA; 2002.

7. Ryden MB, Bossenmaier M, McLachlan C. Aggressive behavior in cognitively impaired nursing home residents. Res Nurs Health 1991;14(2):87-95.

8. Mahoney EK, Hurley A, Volicer L, et al. Development and testing of the Resistiveness to Care Scale. Res Nurs Health. 1999;22(1):27-38.

9. Siem C, Rantz M. J Am Med Dir Assoc. 2013;14:445-446.

10. Morgan DG, Cammer A, Stewart NJ, et al. Journal of the American Medical Directors Association. in press, USA; 2011.

11. Fauth EB, Femia EE, Zarit SH. Resistiveness to Care during Assistance with Activities of Daily Living in Non-institutionalized Persons with Dementia: Associations with Informal Caregivers' Stress and Wellbeing. Aging Ment Health. 2016;20(9):888-898.

12. Cohen MJ, Marx MS, Dakheel AM, et al. Can agitated behavior of nursing home residents with dementia be prevented with the use of standardized stimuli?Journal of the American Geriatrics Society. 2010;58(8):1459-1464.

13. Volicer L, Simard J, Pupa JH, et al. Effects of continuous activity programming on behavioral symptoms of dementia. $J$ Am Med Dir Assoc. 2006;7(7):426-431
14. Yang YP, Lee PP, Chao HC, et al. Comparing the Effects of Cognitive Stimulation, Reminiscence, and Aroma-Massage on Agitation and Depressive Mood in People With Dementia. J Am Med Dir Assoc. 2016;17(8):719-724

15. Gitlin LN, Winter L, Burke J, et al. Tailored activities to manage neuropsychiatric behaviors in persons with dementia and reduce caregiver burden: a randomized pilot study. Am J Geriatr Psychiatry. 2008;16(3):229-239.

16. Sloane PD, Honn VJ, Dwyer SAR, et al. American Journal of Alzheimer's Disease.1995;10:3-11.

17. Desmidt T, Hommet C, Camus V. Pharmacological treatments of behavioral and psychological symptoms of dementia in Alzheimer's disease: role of acetylcholinesterase inhibitors and memantine. Geriatr Psychol Neuropsychiatr Vieil. 2016;14(3):300-306.

18. Cummings J, Lai TJ, Hemrungrojn S, et al. Role of Donepezil in the Management of Neuropsychiatric Symptoms in Alzheimer's Disease and Dementia with Lewy Bodies. CNS Neurosci Ther. 2016;22(3):159-166.

19. Matsunaga S, Kishi $T$, Iwata $N$. Memantine monotherapy for Alzheimer's disease: a systematic review and meta-analysis. PLoS One. 2016;10(4):e0123289.

20. Links KA, Black SE, Graff GA, et al. Neurocase. 2016;19(3):256-261.

21. Li P, Quan W, Zhou YY, et al. Efficacy of memantine on neuropsychiatric symptoms associated with the severity of behavioral varian frontotemporal dementia: A six-month, open-label, self-controlled clinical trial. Exp Ther Med. 2016;12(1):492-498.

22. Matsuzono K, Hishikawa N, Ohta Y, et al. $J$ Alzheimers Dis. 2016;45:771-780.

23. Volicer L, Frijters DH, Van der Steen JT. Relationship between symptoms of depression and agitation in nursing home residents with dementia. Int J Geriatr Psychiatry. 2012;27(7):749-754.

24. Galindo-Garre F, Volicer L, Van der Steen JT. Factors Related to Rejection of Care and Behaviors Directed towards Others: A Longitudinal Study in Nursing Home Residents with Dementia. Dement Geriatr Cogn Dis Extra. 2015;5(1):123-134.

25. Volicer L, Frijters DH, Van der Steen JT. Underdiagnosis and undertreatment of depression in nursing home residents. European Geriatric Medicine. 2011;2:332-337.

26. Booker A, Bohlken J, Rapp MA, et al. Persistence With Antidepressant Drugs in Patients With Dementia: A Retrospective Database Analysis. Int J Clin Pharmacol Ther. 2016;54(5):323-329.

27. Porsteinsson AP, Drye LT, Pollock BG, et al. Effect of citalopram on agitation in Alzheimer disease: the CitAD randomized clinical trial. Journal of the American Medical Association. 2014;311(7):682-691.

28. Leonpacher AK, Peters ME, Drye LT, et al. Effects of Citalopram on Neuropsychiatric Symptoms in Alzheimer's Dementia: Evidence From the CitAD Study. Am J Psychiatry. 2016;173(5):473-480.

29. Lyketsos CG, DelCampo L, Steinberg M, et al. Treating depression in Alzheimer disease: efficacy and safety of sertraline therapy, and the benefits of depression reduction: the DIADS. Arch Gen Psychiatry. 2003;60(7):737-746

30. Kozel, FA, Trivedi MH, Wisniewski SR, et al. Treatment outcomes for older depressed patients with earlier versus late onset of first depressive episode: a Sequenced Treatment Alternatives to Relieve Depression (STAR*D) report. Am J Geriatr Psychiatry. 2008;16(1):58-64.

31. Papakostas GI, Shelton RC, Smith J, et al. Augmentation of antidepressants with atypical antipsychotic medications for treatmentresistant major depressive disorder: a meta-analysis. J Clin Psychiatry. 2007;68(6):826-831. 
32. Jennings L, Grossberg GT. Journal of the American Medical Directors Association. 2013;14:443-449.

33. Ballard C, Hanney ML, Theodoulou M, et al. The dementia antipsychotic withdrawal trial (DART-AD): long-term follow-up of a randomised placebo-controlled trial. Lancet/Neurology. 2009;8(2):151-157.
34. Ray WA, Chung CP, Murray KT, et al. Atypical Antipsychotic Drugs and the Risk of Sudden Cardiac Death. New England Journal of Medicine. 2009;36(3):225-235.

35. Garay RP, Citrome L, Grossberg GT, et al. Expert Opin Investig Drugs. 2016. p. 1-11. 